Fetal Diagnosis ${ }^{\text {and }}$ Therapy
Fetal Diagn Ther 2015;38:241-253

DOI: $10.1159 / 000437053$
Received: February 5, 2015

Accepted after revision: June 17, 2015

Published online: August 1, 2015

\title{
Twenty-Five Years of Fetoscopic Laser Coagulation in Twin-Twin Transfusion Syndrome: A Systematic Review
}

\author{
Joost Akkermans ${ }^{a}$ Suzanne H.P. Peeters ${ }^{a}$ Frans J. Klumper ${ }^{a}$ Enrico Lopriore ${ }^{b}$ \\ Johanna M. Middeldorp ${ }^{a}$ Dick Oepkes ${ }^{a}$ \\ a Department of Obstetrics and ${ }^{b}$ Division of Neonatology, Department of Pediatrics, Leiden University Medical \\ Center, Leiden, The Netherlands
}

\section{Key Words}

Laser therapy · Monochorionic twins · Neonatal outcome .

Systematic review - Twin-twin transfusion syndrome

\begin{abstract}
Objective: The aim of this study was to assess the perinatal outcome of pregnancies with twin-twin transfusion syndrome (TTTS) treated with laser therapy over the past 25 years, and in relation to different techniques used in this time period. Methods: A systematic review of studies reporting on perinatal outcome according to the Meta-Analysis of Observational Studies in Epidemiology (MOOSE) guidelines was conducted. The MEDLINE, Embase and Cochrane Library databases were systematically searched. Comparisons were made in respect to time period and laser technique and Quintero stages. Results: In total, 34 studies reporting on 3,868 monochorionic twin pregnancies were included. The mean survival of both twins increased from 35 to $65 \%$ ( $p=$ 0.012 ) and for at least one twin from 70 to $88 \%(p=0.009)$ over the past 25 years. Mean gestational age at birth remained stable over the years at 32 weeks gestation. Also, we showed a significantly improved perinatal survival with the evolution of the laser technique from non-selective to selective, selective sequential and the Solomon technique $(p=$
\end{abstract}

0.010). Discussion: Since the introduction of laser therapy for TTTS more than two decades ago, perinatal survival improved significantly. Improved outcome is probably associated with several factors, including evolution of the laser technique, learning curve effect, better referral and improved early neonatal care.

(c) 2015 S. Karger AG, Basel

\section{Introduction}

Monochorionic twin pregnancies are at a $10 \%$ risk of developing twin-twin transfusion syndrome (TTTS) [1, 2] due to vascular anastomoses on a shared placenta. Before De Lia et al. [3] proposed fetoscopic laser coagulation of the placental vessels in 1990, serial amnioreduction was considered the only treatment option of polyhydramnios, the most prominent feature of TTTS. Serial amnioreduction was associated with mortality rates up to $60 \%$, a median gestational age (GA) at delivery around 28 weeks and up to $50 \%$ severe neurodevelopment impairment in survivors [4].

\section{J. Akkermans and S.H.P. Peeters contributed equally to this paper.}

\section{KARGER 125}

(c) 2015 S. Karger AG, Base

$1015-3837 / 15 / 0384-0241 \$ 39.50 / 0$

E-Mail karger@karger.com

www.karger.com/fdt
Joost Akkermans, MD, MSc

Department of Obstetrics, Leiden University Medical Center

Albinusdreef 2, PO Box 9600

NL-2300 RC Leiden (The Netherlands)

E-Mail j.akkermans@lumc.nl 
Survival significantly improved after the introduction of laser coagulation by addressing the cause of the problem, making it the accepted treatment of choice for TTTS [5]. However, results are still far from satisfactory, with mortality rates ranging from 20 to $48 \%$, and significant complications, including iatrogenic preterm premature rupture of membranes (PPROM) [6] resulting in preterm delivery before 32 weeks gestation, twin anemia-polycythemia sequence (TAPS) [7], recurrence or reversal of TTTS [8] and adverse long-term neurodevelopmental outcome in $6-18 \%$ of survivors [9].

Since the first publications on fetoscopic laser surgery, several technical modifications have been described. Coagulation of all vessels crossing the inter-twin membrane was abandoned because it led to unnecessary placental loss [10]. In 1998, Quintero et al. [11] introduced the selective laser coagulation technique. This technique, which was rapidly adopted by most fetal therapy centers, aims to save as much functioning placenta tissue as possible by coagulating only true inter-twin vascular anastomoses instead of every vessel crossing the membranous equator. In 2007 the same group proposed the sequential selective laser coagulation technique [12].

Sequential selective laser is an adaptation whereby anastomoses are coagulated in a specific order. The aim is to obliterate the anastomoses in a sequence that allows, at least partly, an intraoperative correction of the hypoperfusion of the donor and hyperperfusion of the recipient. This is achieved by first closing the arteriovenous anastomoses from donor to recipient, starting with the largest ones, followed by the closure of the vein-to-artery anastomoses (e.g. the vessels with a blood flow towards the donor) as the last part of the procedure. In 2008 the Solomon trial [13] was started, introducing a new adaptation to the selective technique. The rationale of the Solomon technique is coagulation of the whole vascular equator from one placenta margin to the other. With the Solomon technique, all laser spots are connected by drawing a laser line, minimizing the chance of residual anastomoses. The study showed that this technique was associated with significantly less residual anastomoses, thereby reducing the risk for TAPS and recurrence of TTTS.

This study focuses on perinatal outcome after laser therapy over the past 25 years and on the impact of the above-mentioned changes in laser treatment strategies on the outcome results. We systematically reviewed all published series since the introduction of laser treatment of TTTS with respect to survival, GA at birth and procedural or postoperative complications in relation to the time and the laser technique used.

\section{Methods}

\section{Data Sources}

Before conduct of the systematic review a detailed protocol that included the search strategies, inclusion and exclusion criteria, outcome parameters and methods of statistical analysis was created. This systematic literature review was performed according to the Meta-Analysis of Observational Studies in Epidemiology (MOOSE) [14], and the Preferred Reporting Items for Systematic Reviews and Meta-Analyses (PRISMA) guidelines [15] where applicable.

\section{Literature Search}

An initial literature search on survival after laser coagulation for TTTS was conducted in MEDLINE, Embase and the Cochrane Library using the PubMed and OVID search engines without restriction on the language or type of publication. Key words and free text searches were performed with combinations of the following key words: survival, perinatal survival, twin-to-twin transfusion syndrome, TTTS, twin-twin transfusion syndrome, fetofetal transfusion, placental anastomoses, laser, laser therapy, laser ablation, SLPCV, SQLPCV, sequential laser, selective laser, fetoscopy, FLOC and photocoagulation. Additionally, reference sections of eligible studies were hand-reviewed for potential eligible studies. Our search included articles published up to May 2014 that reported on pregnancy outcomes after fetoscopic laser coagulation of placental vascular anastomoses.

\section{Inclusion and Exclusion Criteria}

Randomized trials and comparative studies as well as prospective and retrospective case series were considered eligible for inclusion. Reasons for exclusion were studies with insufficient or overlapping data, letters, conference abstracts, review articles and case reports.

\section{Selection and Data Extraction}

All references were independently screened by two reviewers (J. Akkermans and S.H.P. Peeters). Disagreement on the eligibility of a study was resolved by discussion until consensus was reached.

Studies presenting data on twin pregnancies with confirmed monochorionicity by first trimester ultrasound, affected by TTTS according to the Eurofoetus criteria [5] or the Quintero criteria [16] treated with fetoscopic laser coagulation of vascular anastomoses were included.

Studies were selected when presenting at least the number of patients treated and either survival rate of both twins, survival rate of one twin, survival rate of at least one twin or GA at birth. Other important parameters were complications, such as PPROM, GA at laser and laser technique used. In the sporadic event that study results contained also outcomes of triplets (e.g. monochorionic twins affected by TTTS and a singleton), we used the perinatal outcome results of the twins for analysis.

To prevent double counting of cases, we excluded studies reporting outcomes from pregnancies that were treated in overlapping years with other published series from the same centers.

Differences in dual survival, single survival and at least one survival as well as GA at birth were analyzed on a timeline. Five-year intervals were chosen to analyze studies over time. For categorization we used the year the study was concluded as a cut-off value. Survival was analyzed per laser technique used in the series to show the impact of the proposed technical adaptations of the laser treatment. 
Table 1. Studies included in the review

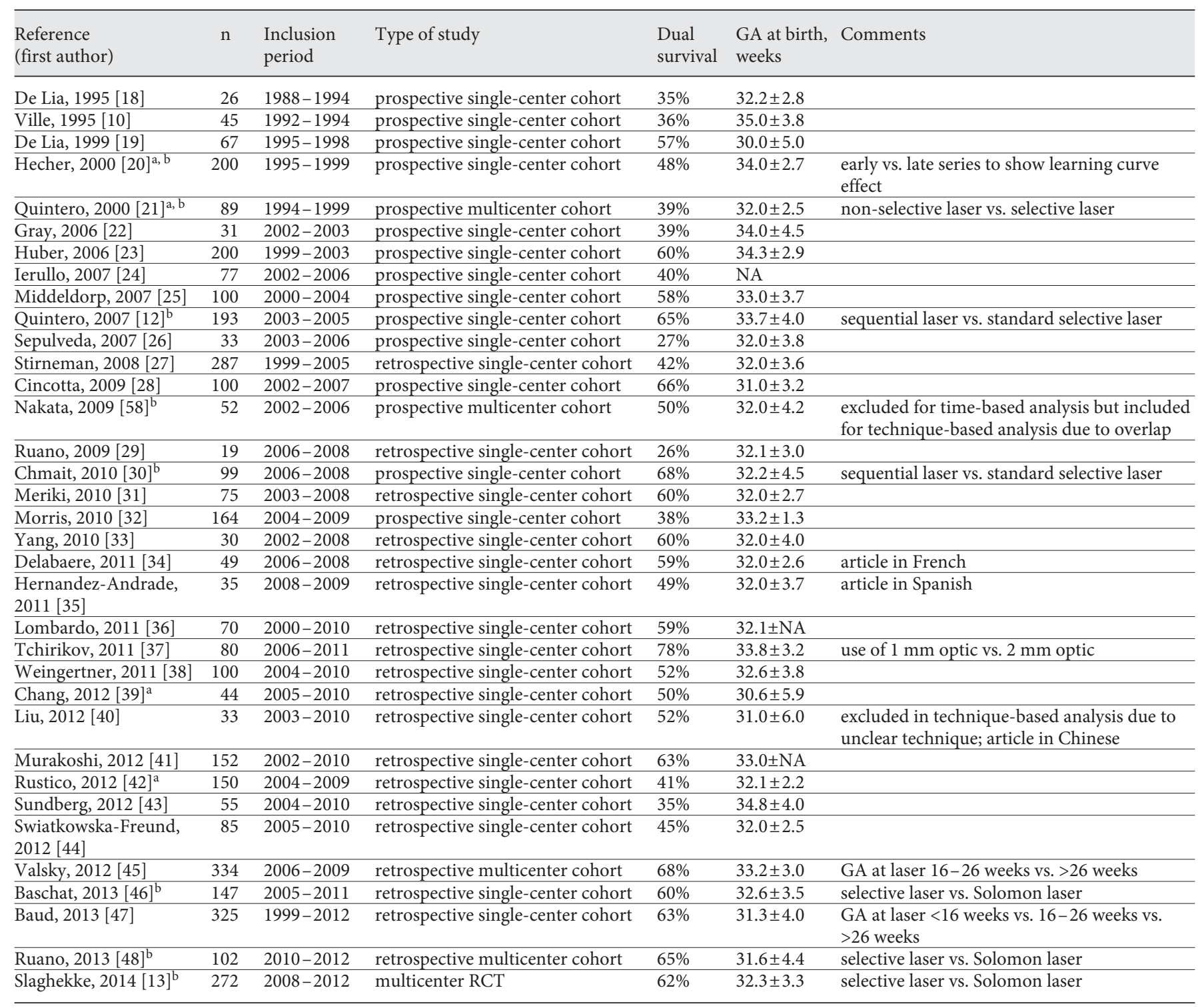

Figures for GA at birth are mean $\pm \mathrm{SD}$. NA = Not assessed; RCT $=$ randomized controlled trial.

${ }^{a}$ These studies described more series over different time periods and were split up in the time-based analyses.

${ }^{\mathrm{b}}$ These studies described comparisons between different techniques.

\section{Statistical Analysis}

Continuous variables were reported as median (range) or mean \pm standard deviation (SD); for synthesis of data, medians (range) were recalculated as means \pm SD using the method described by Hozo et al. [17].

For comparing survival outcomes of different techniques, a cumulative survival rate was calculated and the $95 \%$ confidence intervals (CIs) were estimated using binomial distribution. The survival rates were pooled using the DerSimonian and Laird random-effects models with heterogeneity estimated from the Mantel-Haenszel model.
The results of multiple groups were compared using analysis of variance (ANOVA) statistics. Results of categorical variables were compared using Fisher's exact test or $\chi^{2}$ test, as appropriate. Student's $t$ test was used to compare normally distributed values between two groups. The Mann-Whitney $U$ test was used to compare non-parametric variables. A p value $<0.05$ was considered to indicate statistical significance.

Statistical analysis was performed using SPSS (IBM SPSS Statistics 20 for Windows; IBM, New York, N.Y., 2011) and MS Excel (Microsoft Excel 2010; Microsoft, Redmond, Wash., 2010). This being a literature review, no approval from our Ethics Committee was needed before performing this study. 


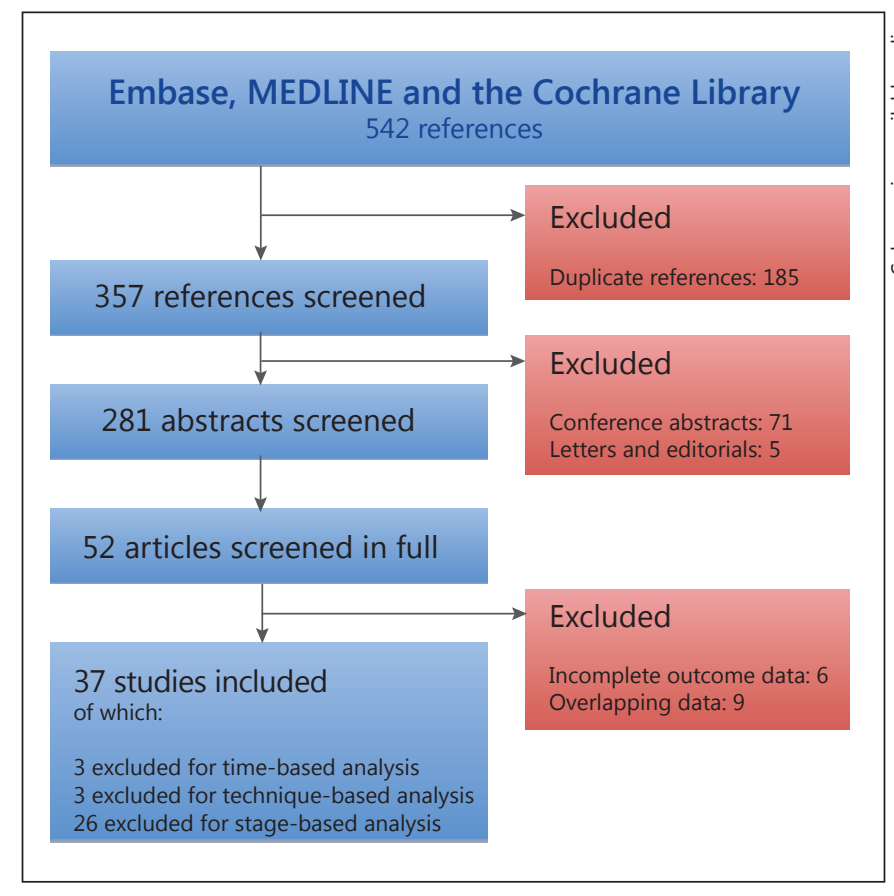

Fig. 1. Flow chart of study selection according to the MOOSE guideline.

\section{Results}

\section{Flow of Study Inclusion}

Figure 1 shows a flow diagram according to the PRISMA statement [15] with the total number of citations retrieved by the search strategy and the number included in the review. After full-text analysis a total of 34 studies were included in the time-based analysis $[10,12,13,18$ 48]. Twelve studies [5, 49-59] presented data overlapping other series, of which one presented data relevant for the technique-based analysis [58].

\section{Study Characteristics}

The characteristics of all included studies are shown in table 1 . One of the studies enrolled was a randomized controlled trial [13]; there were 13 prospective singlecenter cohort studies [10, 12, 18-20, 22-26, 28, 30, 32], 18 retrospective single-center cohort studies $[27,29,31,33-$ $44,46,47,59], 2$ prospective multicenter cohort studies $[21,58]$ and 3 retrospective multicenter cohort studies $[45,48,55]$.

The studies were from the United States, Belgium, Australia, Canada, Spain, Poland, Italy, Taiwan, Germany, The Netherlands, Denmark, the United Kingdom, France, Japan, Mexico, Brazil, China and Chile. The pri- mary outcomes - perinatal survival of at least one or both twins and GA at birth - were well defined in all included studies.

There were three non-English language articles [34, $35,40]$. The language skills of the authors and co-workers (Chinese) were sufficient to analyze these articles.

Three authors described their series in two separate cohorts in order to display their learning curve [20,39, 42]. Eight studies compared different (adaptations of) laser techniques [12, 13, 20, 21, 30, 46, 48, 58].

Baud et al. [47] compared the outcomes of early, late and conventional selective laser surgery defined as performed before 17 weeks gestation, after 26 weeks gestation and between 17 and 26 weeks.

For the overlapping series of Nakata et al. [58] and Murakoshi et al. [41], we used the latter for the time-based analysis and the former for the technique-based analysis. For the study of Liu et al. [40] it was unclear what technique was used and therefore it was excluded in the technique-based analysis.

\section{Primary Outcome}

A total of 3,868 women with a monochorionic twin pregnancy complicated by TTTS treated with fetoscopic laser coagulation were included in the time-based analysis; the sample size per study ranged from 19 to 334 women. The median time span of study inclusion for all studies was 4 years (interquartile range 2-6).

The mean GA at the time of surgery was $20.9 \pm 1.9$ weeks. Combining all series, the mean perinatal survival of both twins, one twin and at least one twin was $52 \pm$ $14.8 \%, 29 \pm 10.5 \%$ and $81 \pm 8.3 \%$, respectively. The overall survival of fetuses was 5,348/7,736 (69.1\%). Figure 2a displays a forest plot with double twin survival rates in all included studies subdivided into time groups based on their study period, and the difference between the time periods. Figure $2 \mathrm{~b}$ displays the forest plot of single twin survival rates.

For both twins survival rates significantly increased from $31 \%(1990-1995)$ to $62 \%(2011-2014)(\mathrm{p}<0.001)$, and survival rates for at least one twin significantly increased from $70 \%(1990-1995)$ to $88 \%(2011-2014)$ ( $\mathrm{p}=$ $0.009)$. No significant change in survival of one twin was

Fig. 2. a Forest plot showing double twin survival rates over 25 years of laser therapy for TTTS subdivided into 5-year time periods. b Forest plot showing single twin survival rates over 25 years of laser therapy for TTTS subdivided into 5 -year time periods.

(For figures $2 a$ and $b$ see next pages.) 


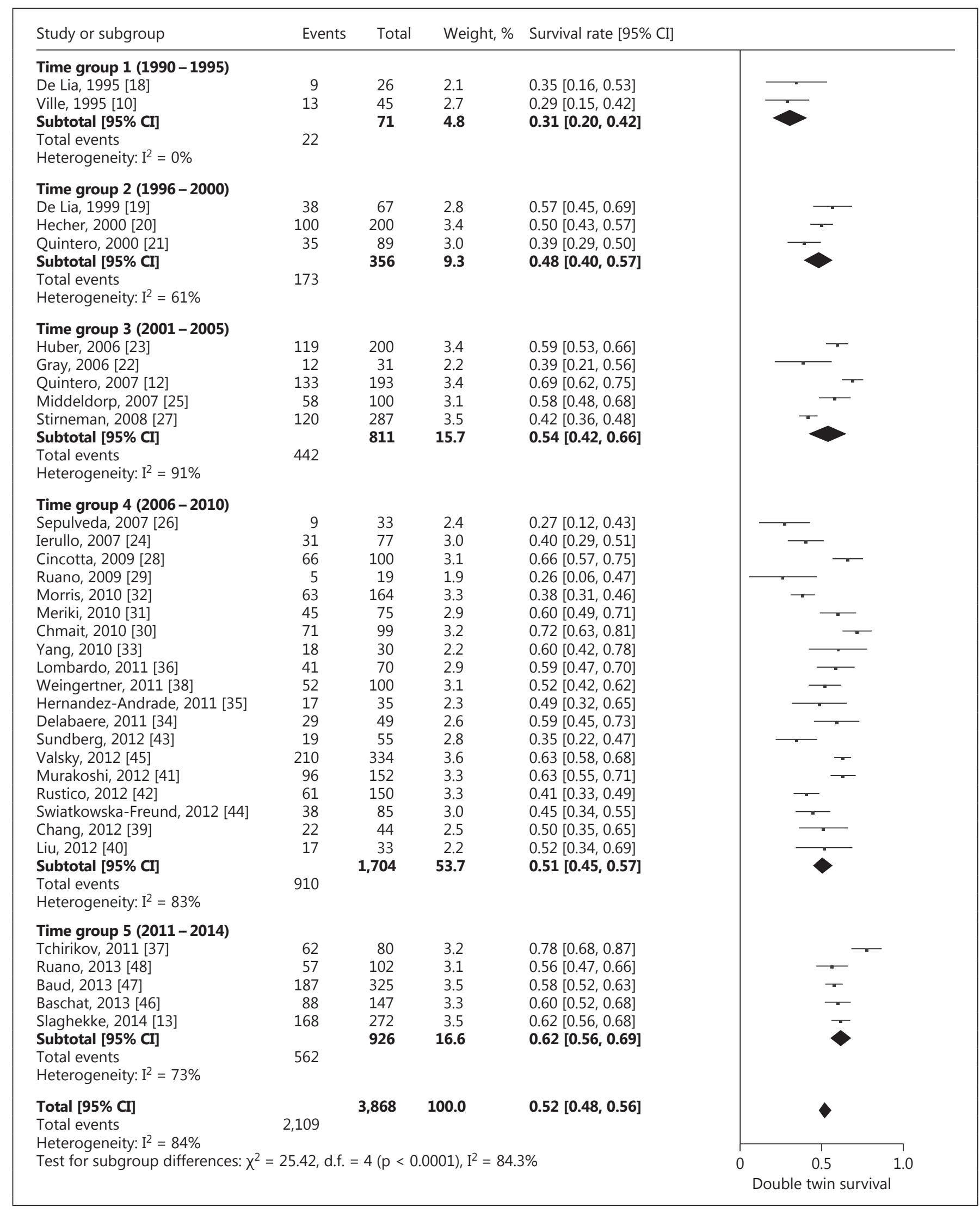




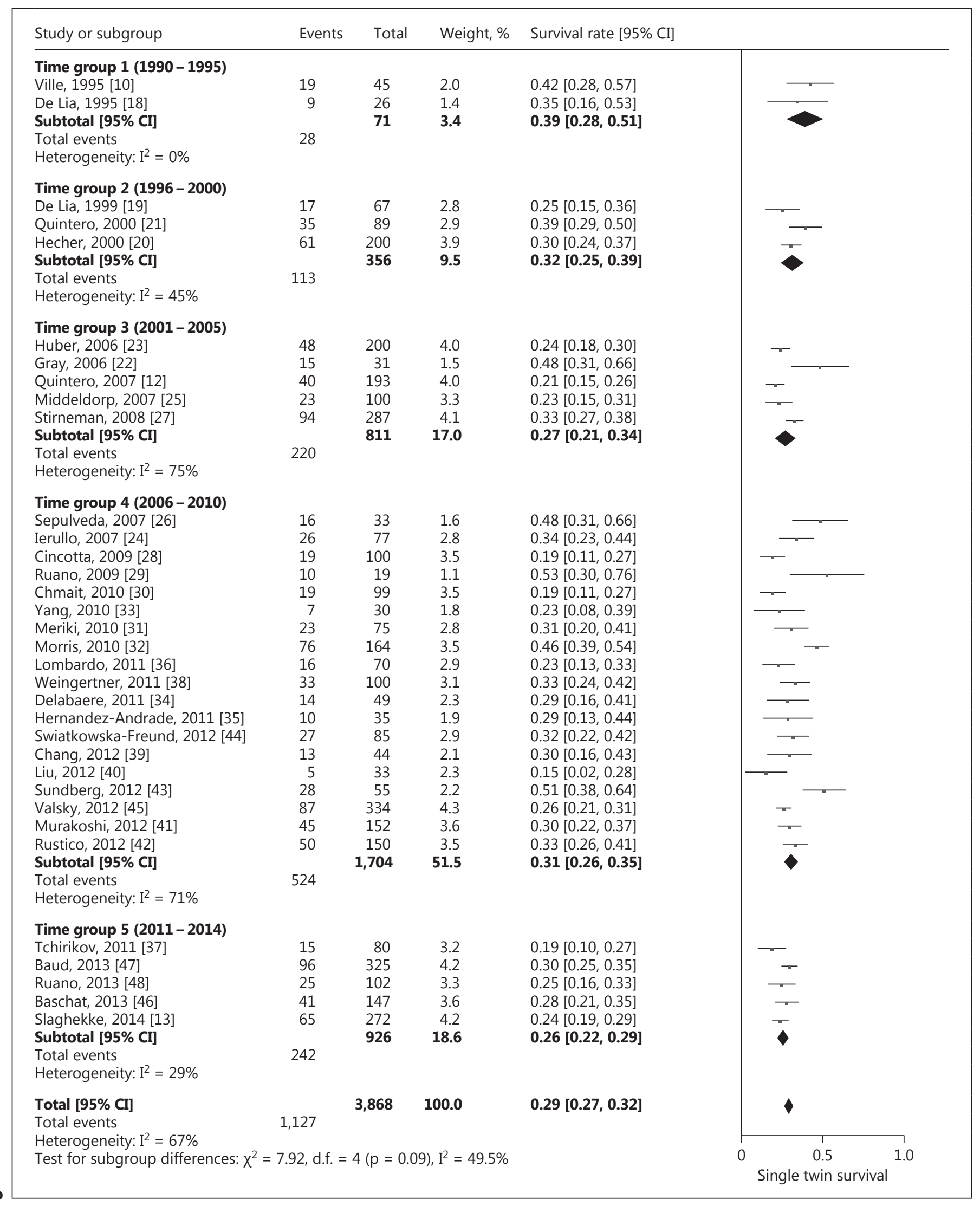




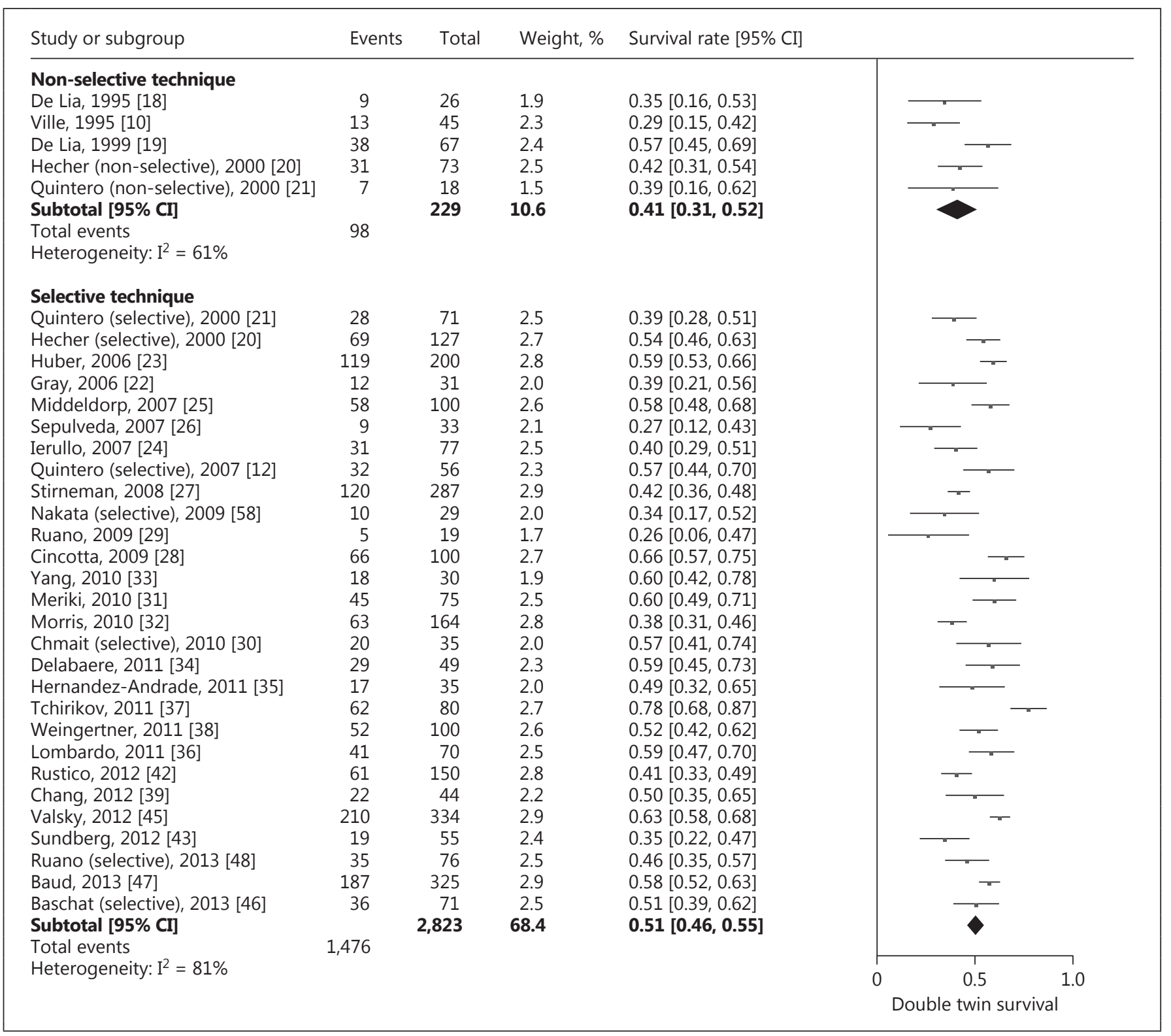

Fig. 3. a Forest plot showing double twin survival rates subdivided by the laser technique used.

(For second part of figure 3 a see next page.)

seen between 1990 and 1995 (39\%) and between 2011 and $2014(26 \%)(p=0.09)$.

The overall mean GA at birth of all series was $32.4 \pm$ 1.3 weeks. GA at birth did not change in time for the included series $(\mathrm{p}=0.226)$.

\section{Laser Technique}

Thirty-four studies clearly specified their laser technique and eight of these studies compared two groups for which different laser techniques were used [12, 13, 20, 21,
$30,46,48,58]$. These groups were analyzed separately, resulting in 41 subgroups describing survival results for different laser techniques. The non-selective laser technique was used in five series [10, 18-21], 28 series used the selective laser technique [12, 20-39, 42, 43, 45-48, 58], the selective sequential technique was used in five series $[12,13,30,41,44]$, and three series used the Solomon technique $[13,46,48]$.

Figure 3a shows a forest plot with the individual studies and the inter-study heterogeneity per technique as 


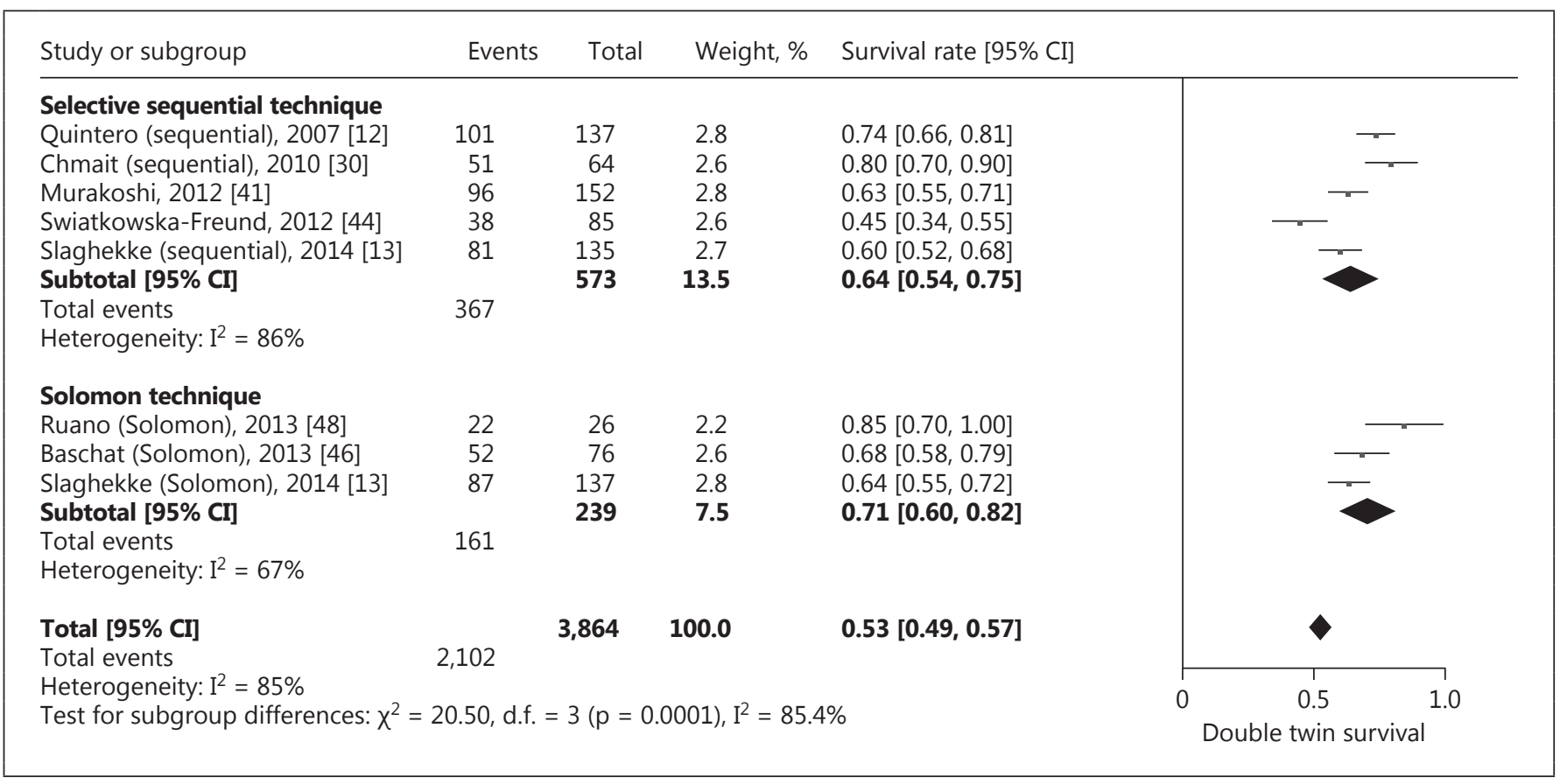

well as the subgroup difference and heterogeneity between the subgroups for double twin survival. Figure $3 \mathrm{~b}$ shows a forest plot with the results for single twin survival. Survival of both twins improved significantly ( $\mathrm{p}=$ 0.0001 ) over the course of the introduction of new or modified techniques to the detriment of survival of only one twin $(\mathrm{p}=0.01)$. Overall a gradual improvement in survival of at least one twin was seen for the newer techniques $(\mathrm{p}=0.004)$.

\section{Complications}

Reports on post-treatment complications after laser therapy were not readily available in all studies. Only 12 (33\%) of the included studies reported data on PPROM. Definitions ranged from ' $<37$ weeks gestation' to 'within 7 days after fetoscopy', making comparison of these results impossible [13, 27, 29, 31, 32, 35, 36, 38, 39, 42, 46, 47].

\section{Discussion}

In this review of all published series reporting on outcomes after fetoscopic laser treatment for TTTS, we found a significant improvement in survival of both twins and at least one twin over the past 25 years. This study also shows a significant improvement in survival of both twins with the more recently developed laser techniques.
In 1990, De Lia et al. [3] published the first results of fetoscopic laser therapy as an alternative for serial amnioreduction for the treatment of TTTS. Since then the technique has undergone a variety of modifications.

The shown improvement in survival is likely multifactorial and potentially affected by different forms of bias. There are several important hypotheses to explain the improvement in perinatal survival after laser treatment in time. First of all, adaptations in laser technique such as indicated above are likely to affect survival, however the only way to demonstrate this true effect is to perform a randomized controlled trial adequately powered for perinatal survival.

Secondly, an important factor affecting treatment results is the learning curve effect. In principle, novice surgeons are assumed to perform surgery less safely and efficiently than more experienced colleagues. A learning curve represents the improvement of both the operators, from experience and practice, and, equally as important, the performance of the entire team at managing pregnancies with TTTS. Better teamwork, multidisciplinary discussion with colleagues from the neonatology department (including international audits), stimulation, controllability and continuity may have been beneficial factors [57].

Furthermore, since laser therapy has been accepted as the preferred treatment option, knowledge and aware- 


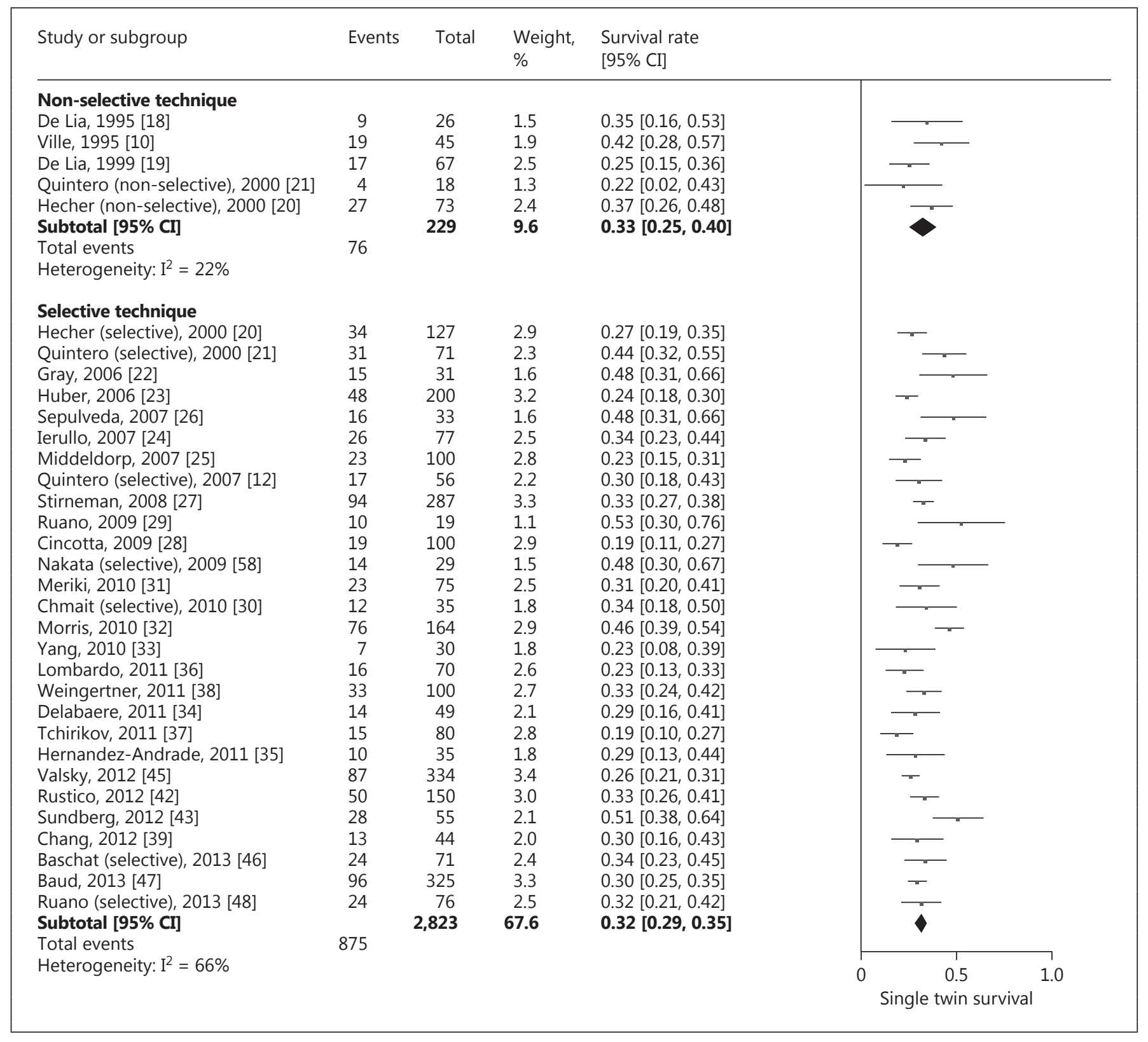

Fig. 3. b Forest plot showing single twin survival rates subdivided by the laser technique used.

(For second part of figure $3 b$ see next page.)

ness in remote centers not offering this highly specialized treatment has grown. Increased awareness may have resulted in improved timely referral and a decreasing number of cases with advanced disease and poor outcomes.

With the acceptance of laser surgery as the best treatment thus far, over the years increasing number of centers started to offer this procedure. Since TTTS is rare and both the surgical procedure as well as careful selection of cases and optimal timing of treatment is complex, con- centration of care in specialized maternal-fetal medicine centers has been advocated. With the most recent survival rates as a benchmark, (real-time) monitoring and quality control are essential to prevent a more widespread use of this technique, at least temporarily, from leading to less favorable outcome due to learning curve effects and small numbers.

The finding that newer techniques have better perinatal survival results could be attributable to a true improve- 


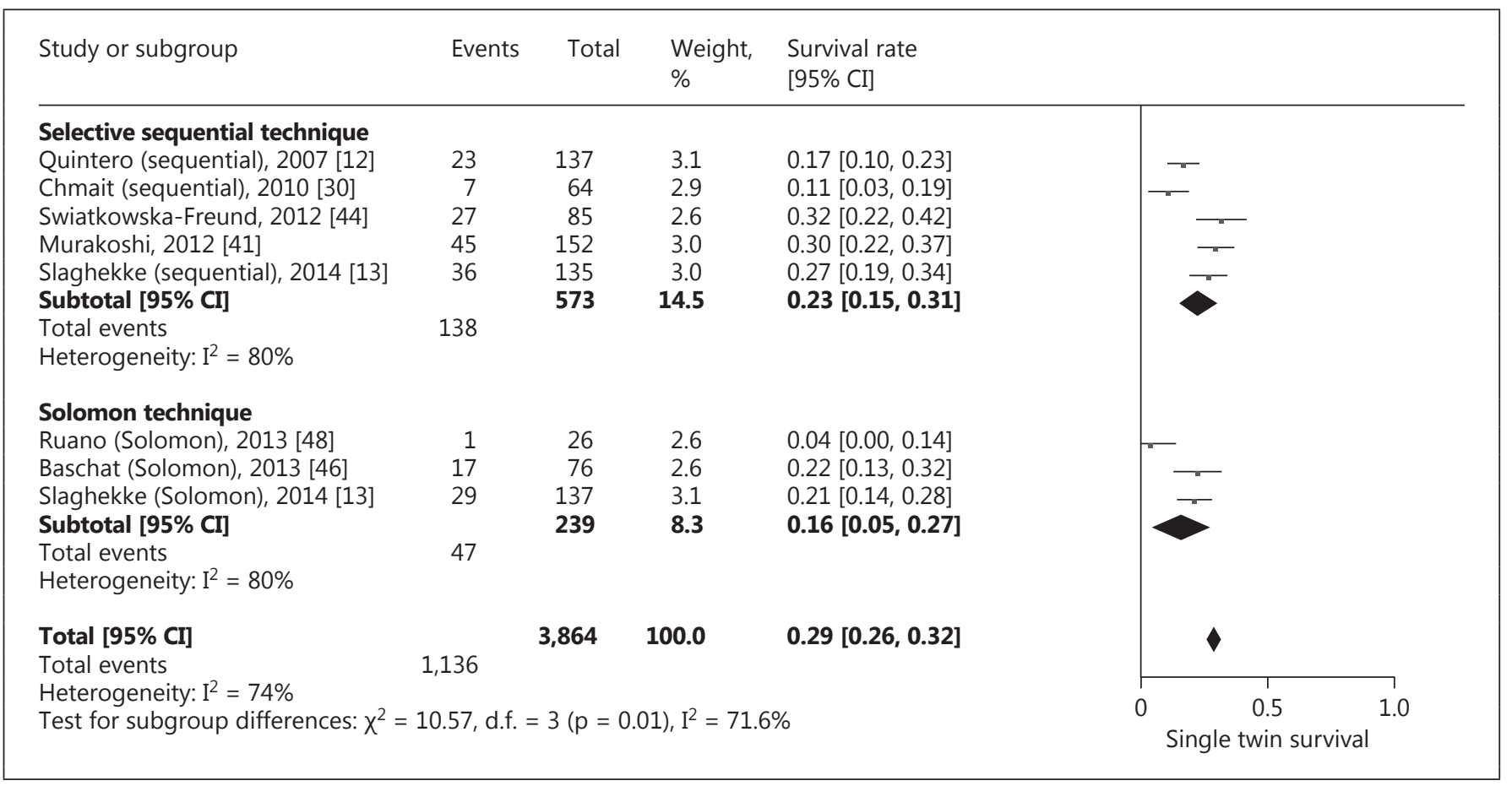

ment in the technique. However this effect could be positively affected by the fact that new techniques are, in general, introduced and adopted sooner by the more experienced therapists after completion of their learning curve and thus likely perform better. Another important factor influencing this improved survival is based on case selection in series comparing two techniques, which was evident in some studies on the sequential laser technique [60].

With this study we hope to set a benchmark level which established and starting centers can compare their individual results with. Regular structural reflection on one's own practice is essential to prevent late detection of suboptimal performance. If less favorable outcomes are noticed, a quality cycle including further education, supervision of practice and improvement of learning environment should be initiated. We encourage starting up centers as well as established centers to share their performance for peer review and to publish their series in order to keep updating the benchmark for other centers [61].

Unfortunately, data on post-treatment complications such as TAPS, recurrent TTTS or PPROM were often not available in the reported studies or lacked uniform definitions. Iatrogenic PPROM is generally assumed to be one of the most important causes of premature delivery after laser therapy [6]. To gain better insight into the important complications of laser treatment, it is crucial that we use systematic methods of reporting. Incidences are low and knowledge is largely based on small series. In order to conduct systematic reviews in these areas, definitions need to be uniform when it comes to perinatal survival (e.g. alive at 28 days after birth), PPROM (e.g. before 32 weeks gestation), TAPS and recurrent TTTS.

This study has some important limitations. Our findings could be influenced by publication bias. Centers that are still in their learning curve, or otherwise have less favorable results, might be hesitant to publish their series when they underperform compared to the published series of established centers. Also, the data may reflect selection bias. Less experienced centers may only treat less difficult cases and refer difficult cases to experienced centers, resulting in better survival in their centers and decreased survival in the latter.

The past decades have also shown significant improvements regarding (early) neonatal care resulting in overall better outcomes after preterm birth [62-64]. The effect of the above-mentioned factors are very difficult to quantify and should be taken into account when interpreting the results of this study.

Another limitation is the inclusion of series that have a large time span of data collection. This might have decreased the differences in survival over time when later series include the learning curve phase of the center. 
Evaluation of technical or other adaptations of surgical techniques using historic controls is hampered by bias caused by increasing experience over time, the learning curve effect and improved neonatal care. The value of meta-analysis is highly dependent on the quality of the included studies. Most of the introduced techniques and adaptations have not been evaluated in randomized controlled trials. Comparison of survival outcomes of different techniques based on data from non-comparative observational studies is potentially hampered by high interstudy heterogeneity, as found in this study. Due to the nature of the data, statistical correction is impossible. Interpretation of the results should be done with caution and can only be used to generate hypotheses.

The treatment of TTTS yielded a fair improvement in perinatal survival with the introduction of laser surgery over two decades ago. This review shows a significant increase in perinatal survival since then. Combining all published series, as a benchmark, perinatal survival of at least one twin after laser therapy can be achieved in 81$88 \%$ of pregnancies and survival of both twins in $52-54 \%$ of pregnancies. The median GA at delivery in these series was 32.4 weeks. Nevertheless, we believe that significant improvement opportunities prevail and we see challenges in improving instrumentation and technology for the treatment of TTTS to increase survival of both twins and, almost equally important, in prolonging pregnancies beyond 34 weeks gestation. Survival and short-term neonatal morbidity should not be the only goals. The ultimate goal should be 'disease-free survival' and focus on reducing the rate of neurodevelopmental impairment. We sug- gest institutions to focus on long-term pediatric neurodevelopmental outcomes. Follow-up into childhood is indispensable to determine outcome in terms of motor, cognitive and behavioral development [65].

Fetoscopic laser treatment is often hindered by technical difficulties such as reduced visibility due to stained amniotic fluid or poor accessibility of some anastomoses due to placenta location or the position of fetal parts on the vascular equator [66]. Possibly, such limitations may affect the outcome results of the treatment. Technological innovations may aid us to overcome these limitations and help us improve our outcomes. Remarkably, technological innovations in instrumentation and equipment, common in the field of laparoscopic surgery, appear to be virtually absent in the fetoscopic treatment of TTTS. The equipment used 25 years ago is almost identical to what we use today. A lack of interest from commercial companies paired with complicated licensing issues for use in pregnancy may play a role.

\section{Acknowledgement}

This research was supported by the Dutch Technology Foundation STW, which is part of the Netherlands Organization for Scientific Research (NWO), which is partly funded by the Ministry of Economic Affairs.

\section{Disclosure Statement}

None of the authors have any conflict of interest.

\section{References}

$>1$ Lewi L, Gucciardo L, Van Mieghem T, De Koninck P, Beck V, Medek H, Van Schoubroeck D, Devlieger R, De Catte L, Deprest J: Monochorionic diamniotic twin pregnancies: natural history and risk stratification. Fetal Diagn Ther 2010;27:121-133.

$\checkmark 2$ Rossi AC, D’Addario V: Laser therapy and serial amnioreduction as treatment for twintwin transfusion syndrome: a metaanalysis and review of literature. Am J Obstet Gynecol 2008;198:147-152.

3 De Lia JE, Cruikshank DP, Keye WR Jr: Fetoscopic neodymium:YAG laser occlusion of placental vessels in severe twin-twin transfusion syndrome. Obstet Gynecol 1990;75:1046-1053.

4 Roberts D, Gates S, Kilby M, Neilson JP: Interventions for twin-twin transfusion syndrome: a Cochrane review. Ultrasound Obstet Gynecol 2008;31:701-711.
5 Senat MV, Deprest J, Boulvain M, Paupe A, Winer N, Ville Y: Endoscopic laser surgery versus serial amnioreduction for severe twinto-twin transfusion syndrome. N Engl J Med 2004;351:136-144.

-6 Beck V, Lewi P, Gucciardo L, Devlieger R: Preterm prelabor rupture of membranes and fetal survival after minimally invasive fetal surgery: a systematic review of the literature. Fetal Diagn Ther 2012;31:1-9.

-7 Slaghekke F, Kist WJ, Oepkes D, Pasman SA, Middeldorp JM, Klumper FJ, Walther FJ, Vandenbussche FP, Lopriore E: Twin anemia-polycythemia sequence: diagnostic criteria, classification, perinatal management and outcome. Fetal Diagn Ther 2010;27:181-190.
$>8$ Walsh CA, McAuliffe FM: Recurrent twintwin transfusion syndrome after selective fetoscopic laser photocoagulation: a systematic review of the literature. Ultrasound Obstet Gynecol 2012;40:506-512.

-9 van Klink JM, Koopman HM, van Zwet EW, Middeldorp JM, Walther FJ, Oepkes D, Lopriore E: Improvement in neurodevelopmental outcome in survivors of twin-twin transfusion syndrome treated with laser surgery. Am J Obstet Gynecol 2014;210:540.e17.

10 Ville Y, Hyett J, Hecher K, Nicolaides K: Preliminary experience with endoscopic laser surgery for severe twin-twin transfusion syndrome. N Engl J Med 1995;332:224-227. 
11 Quintero RA, Morales WJ, Mendoza G, Allen M, Kalter CS, Giannina G, Angel JL: Selective photocoagulation of placental vessels in twintwin transfusion syndrome: evolution of a surgical technique. Obstet Gynecol Surv 1998; 53(suppl 12):S97-S103.

12 Quintero RA, Ishii K, Chmait RH, Bornick PW, Allen MH, Kontopoulos EV: Sequential selective laser photocoagulation of communicating vessels in twin-twin transfusion syndrome. J Matern Fetal Neonatal Med 2007; 20:763-768.

13 Slaghekke F, Lopriore E, Lewi L, Middeldorp JM, van Zwet EW, Weingertner AS, Klumper FJ, DeKoninck P, Devlieger R, Kilby MD, Rustico MA, Deprest J, Favre R, Oepkes D: Fetoscopic laser coagulation of the vascular equator versus selective coagulation for twinto-twin transfusion syndrome: an open-label randomised controlled trial. Lancet 2014;383: 2144-2151.

- 14 Stroup DF, Berlin JA, Morton SC, Olkin I, Williamson GD, Rennie D, Moher D, Becker BJ, Sipe TA, Thacker SB: Meta-analysis of observational studies in epidemiology: a proposal for reporting. Meta-analysis Of Observational Studies in Epidemiology (MOOSE) group. JAMA 2000;283:2008-2012.

-15 Moher D, Liberati A, Tetzlaff J, Altman DG; PRISMA Group: Preferred reporting items for systematic reviews and meta-analyses: the PRISMA statement. Ann Intern Med 2009; 151:264-269, W264.

16 Quintero RA, Morales WJ, Allen MH, Bornick PW, Johnson PK, Kruger M: Staging of twin-twin transfusion syndrome. J Perinatol 1999; 19:550-555.

-17 Hozo SP, Djulbegovic B, Hozo I: Estimating the mean and variance from the median, range, and the size of a sample. BMC Med Res Methodol 2005;5:13.

18 De Lia JE, Kuhlmann RS, Harstad TW, Cruikshank DP: Fetoscopic laser ablation of placental vessels in severe previable twin-twin transfusion syndrome. Am J Obstet Gynecol 1995; 172:1202-1208; discussion 1208-1211.

$\checkmark 19$ De Lia JE, Kuhlmann RS, Lopez KP: Treating previable twin-twin transfusion syndrome with fetoscopic laser surgery: outcomes following the learning curve. J Perinat Med 1999; 27:61-67.

20 Hecher K, Diehl W, Zikulnig L, Vetter M, Hackeloer BJ: Endoscopic laser coagulation of placental anastomoses in 200 pregnancies with severe mid-trimester twin-to-twin transfusion syndrome. Eur J Obstet Gynecol Reprod Biol 2000;92:135-139.

-21 Quintero RA, Comas C, Bornick PW, Allen $\mathrm{MH}$, Kruger M: Selective versus non-selective laser photocoagulation of placental vessels in twin-to-twin transfusion syndrome. Ultrasound Obstet Gynecol 2000;16:230-236.

-22 Gray PH, Cincotta R, Chan FY, Soong B: Perinatal outcomes with laser surgery for twintwin transfusion syndrome. Twin Res Hum Genet 2006;9:438-443.
23 Huber A, Diehl W, Bregenzer T, Hackeloer BJ, Hecher K: Stage-related outcome in twintwin transfusion syndrome treated by fetoscopic laser coagulation. Obstet Gynecol 2006;108:333-337.

24 Ierullo AM, Papageorghiou AT, Bhide A, Fratelli N, Thilaganathan B: Severe twin-twin transfusion syndrome: outcome after fetoscopic laser ablation of the placental vascular equator. BJOG 2007;114:689-693.

25 Middeldorp JM, Sueters M, Lopriore E, Klumper FJCM, Oepkes D, Devlieger R, Kanhai $\mathrm{HHH}$, Vandenbussche FPHA: Fetoscopic laser surgery in 100 pregnancies with severe twin-to-twin transfusion syndrome in the Netherlands. Fetal Diagn Ther 2007;22:190194.

26 Sepulveda W, Wong AE, Dezerega V, Devoto JC, Alcalde JL: Endoscopic laser surgery in severe second-trimester twin-twin transfusion syndrome: a three-year experience from a Latin American center. Prenat Diagn 2007;27: 1033-1038.

27 Stirnemann JJ, Nasr B, Quarello E, Ortqvist L, Nassar M, Bernard JP, Ville Y: A definition of selectivity in laser coagulation of chorionic plate anastomoses in twin-to-twin transfusion syndrome and its relationship to perinatal outcome. Am J Obstet Gynecol 2008;198: 62.e1-6.

28 Cincotta RB, Gray PH, Gardener G, Soong B, Chan FY: Selective fetoscopic laser ablation in 100 consecutive pregnancies with severe twin-twin transfusion syndrome. Aust N Z J Obstet Gynaecol 2009;49:22-27.

29 Ruano R, Brizot Mde L, Liao AW, Zugaib M: Selective fetoscopic laser photocoagulation of superficial placental anastomoses for the treatment of severe twin-twin transfusion syndrome. Clinics (Sao Paulo) 2009;64:9196.

30 Chmait RH, Khan A, Benirschke K, Miller D, Korst LM, Goodwin TM: Perinatal survival following preferential sequential selective laser surgery for twin-twin transfusion syndrome. J Matern Fetal Neonatal Med 2010;23: $10-16$.

31 Meriki N, Smoleniec J, Challis D, Welsh AW: Immediate outcome of twin-twin transfusion syndrome following selective laser photocoagulation of communicating vessels at the NSW Fetal Therapy Centre. Aust N Z J Obstet Gynaecol 2010;50:112-119.

32 Morris RK, Selman TJ, Kilby MD: Influences of experience, case load and stage distribution on outcome of endoscopic laser surgery for TTTS - a review. Ahmed S et al. Prenatal Diagnosis 2010. Prenat Diagn 2010;30:808-809.

33 Yang X, Leung TY, Ngan Kee WD, Chen M, Chan LW, Lau TK: Fetoscopic laser photocoagulation in the management of twin-twin transfusion syndrome: local experience from Hong Kong. Hong Kong Med J 2010;16:275281.
34 Delabaere A, Accoceberry M, Niro J, Velemir L, Laurichesse-Delmas H, Coste K, Boeuf B, Labbe A, Storme B, Lemery D, Gallot D: Favourable outcome after fetoscopic laser surgery for twin-twin transfusion syndrome: experience of an emerging centre. Gynecol Obstet Fertil 2011;39:482-485.

35 Hernandez-Andrade E, Guzman-Huerta M, Benavides-Serralde JA, Paez-Serralde F, Camargo-Marin L, Acevedo-Gallegos S, Moreno-Alvarez O, Mancilla-Ramirez J: Laser ablation of the placental vascular anastomoses for the treatment of twin-to-twin transfusion syndrome. Rev Invest Clin 2011;63:46-52.

36 Lombardo ML, Watson-Smith DJ, Muratore CS, Carr SR, O’Brien BM, Luks FI: Laser ablation of placental vessels in twin-to-twin transfusion syndrome: a paradigm for endoscopic fetal surgery. J Laparoendosc Adv Surg Tech A 2011;21:869-872.

- 37 Tchirikov M, Oshovskyy V, Steetskamp J, Falkert A, Huber G, Entezami M: Neonatal outcome using ultrathin fetoscope for laser coagulation in twin-to-twin-transfusion syndrome. J Perinat Med 2011;39:725-730.

38 Weingertner AS, Kohler A, Mager C, Miry C Viville B, Kohler M, Hunsinger MC, Hornecker F, Bouffet N, Trastour S, Neumann M, Roth F, Bartolomei C, Favre R: Fetoscopic laser coagulation in 100 consecutive monochorionic pregnancies with severe twin-to-twin transfusion syndrome. J Gynecol Obstet Biol Reprod (Paris) 2011;40:444-451.

39 Chang YL, Chao AS, Chang SD, Hsieh PC, Wang CN: Short-term outcomes of fetoscopic laser surgery for severe twin-twin transfusion syndrome from Taiwan single center experience: demonstration of learning curve effect on the fetal outcomes. Taiwan J Obstet Gynecol 2012;51:350-353.

40 Liu XX, Lau TK, Wang HF, Wong SM, Leung TY: Fetoscopic guided laser occlusion for twin-to-twin transfusion syndrome in 33 cases. Zhonghua Fu Chan Ke Za Zhi 2012;47: 587-591.

41 Murakoshi T, Matsushita M, Shinno T, Naruse $\mathrm{H}$, Nakayama S, Torii Y: Fetoscopic laser photocoagulation for the treatment of twintwin transfusion syndrome in monochorionic twin pregnancies. Open Med Devices J 2012; $4: 4-59$.

42 Rustico MA, Lanna MM, Faiola S, Schena V, Dell'Avanzo M, Mantegazza V, Parazzini C, Lista G, Scelsa B, Consonni D, Ferrazzi E: Fetal and maternal complications after selective fetoscopic laser surgery for twin-to-twin transfusion syndrome: a single-center experience. Fetal Diagn Ther 2012;31:170-178.

43 Sundberg K, Sogaard K, Jensen LN, Schou $\mathrm{KV}$, Jorgensen C: Invasive treatment in complicated monochorionic twin pregnancies: indications and outcome of 120 consecutively treated pregnancies. Acta Obstet Gynecol Scand 2012;91:1201-1205. 
-44 Swiatkowska-Freund M, Pankrac Z, Preis K: Results of laser therapy in twin-to-twin transfusion syndrome: our experience. J Matern Fetal Neonatal Med 2012;25:1917-1920.

45 Valsky DV, Eixarch E, Martinez-Crespo JM, Acosta ER, Lewi L, Deprest J, Gratacos E: Fetoscopic laser surgery for twin-to-twin transfusion syndrome after 26 weeks of gestation. Fetal Diagn Ther 2012;31:30-34.

46 Baschat AA, Barber J, Pedersen N, Turan OM, Harman CR: Outcome after fetoscopic selective laser ablation of placental anastomoses vs equatorial laser dichorionization for the treatment of twin-to-twin transfusion syndrome. Am J Obstet Gynecol 2013;209:234.e1-8.

$\checkmark 47$ Baud D, Windrim R, Keunen J, Kelly EN, Shah P, van Mieghem T, Seaward PG, Ryan G: Fetoscopic laser therapy for twin-twin transfusion syndrome before 17 and after 26 weeks' gestation. Am J Obstet Gynecol 2013;208: 197.e1-7.

-48 Ruano R, Rodo C, Peiro JL, Shamshirsaz AA, Haeri S, Nomura ML, Salustiano EM, de Andrade KK, Sangi-Haghpeykar H, Carreras E, Belfort MA: Fetoscopic laser ablation of placental anastomoses in twin-twin transfusion syndrome using 'Solomon technique'. Ultrasound Obstet Gynecol 2013;42:434-439.

49 Ville Y, Hecher K, Gagnon A, Sebire N, Hyett J, Nicolaides K: Endoscopic laser coagulation in the management of severe twin-to-twin transfusion syndrome. Br J Obstet Gynaecol 1998; 105:446-453.

-50 Yamamoto M, El Murr L, Robyr R, Leleu F, Takahashi Y, Ville Y: Incidence and impact of perioperative complications in 175 fetoscopyguided laser coagulations of chorionic plate anastomoses in fetofetal transfusion syndrome before 26 weeks of gestation. Am J Obstet Gynecol 2005;193:1110-1116.

-51 Crombleholme TM, Shera D, Lee H, Johnson M, D'Alton M, Porter F, Chyu J, Silver R, Abuhamad A, Saade G, Shields L, Kauffman D, Stone J, Albanese CT, Bahado-Singh R, Ball RH, Bilaniuk L, Coleman B, Farmer D, Feldstein V, Harrison MR, Hedrick H, Livingston J, Lorenz RP, Miller DA, Norton ME, Polzin WJ, Robinson JN, Rychik J, Sandberg PL, Seri I, Simon E, Simpson LL, Yedigarova L, Wilson RD, Young B: A prospective, randomized, multicenter trial of amnioreduction vs. selective fetoscopic laser photocoagulation for the treatment of severe twin-twin transfusion syndrome. Am J Obstet Gynecol 2007; 197:396.e1-9.
52 Muratore CS, Carr SR, Lewi L, Delieger R, Carpenter M, Jani J, Deprest JA, Luks FI: Survival after laser surgery for twin-to-twin transfusion syndrome: when are they out of the woods? J Pediatr Surg 2009;44:66-69; discussion 70 .

53 Sago H, Hayashi S, Saito M, Hasegawa H, Kawamoto H, Kato N, Nanba Y, Ito Y, Takahashi Y, Murotsuki J, Nakata M, Ishii K, Murakoshi $\mathrm{T}$ : The outcome and prognostic factors of twin-twin transfusion syndrome following fetoscopic laser surgery. Prenat Diagn 2010;30:1185-1191.

54 Skupski D, Luks F, Walker M, Papanna R, Bebbington M, Ryan G, O'Shaughnessy R, Moldenhauer J, Bahtiyar O: Pre-operative predictors of death in twin-twin transfusion syndrome treated with laser ablation of placental anastomoses. Prenat Diagn 2010;30:S1.

55 Chmait RH, Kontopoulos EV, Korst LM, Llanes A, Petisco I, Quintero RA: Stage-based outcomes of 682 consecutive cases of twintwin transfusion syndrome treated with laser surgery: the USFetus experience. Am J Obstet Gynecol 2011;204:393.e1-6.

56 Tchirikov M, Oshovskyy V, Steetskamp J, Thale V: Neonatal outcome following longdistance air travel for fetoscopic laser coagulation treatment of twin-to-twin transfusion syndrome. Int J Gynaecol Obstet 2012;117: 260-263.

57 Peeters SH, Van Zwet EW, Oepkes D, Lopriore E, Klumper FJ, Middeldorp JM: Learning curve for fetoscopic laser surgery using cumulative sum analysis. Acta Obstet Gynecol Scand 2014;93:705-711.

58 Nakata M, Murakoshi T, Sago H, Ishii K, Takahashi Y, Hayashi S, Murata S, Miwa I, Sumie M, Sugino N: Modified sequential laser photocoagulation of placental communicating vessels for twin-twin transfusion syndrome to prevent fetal demise of the donor twin. J Obstet Gynaecol Res 2009;35:640-647.

59 Wagner MM, Lopriore E, Klumper FJ, Oepkes D, Vandenbussche FP, Middeldorp JM: Short- and long-term outcome in stage 1 twin-to-twin transfusion syndrome treated with laser surgery compared with conservative management. Am J Obstet Gynecol 2009; 201:286.e1-6.

60 Akkermans J, Peeters SH, Klumper FJ, Middeldorp JM, Lopriore E, Oepkes D: Is the sequential laser technique for twin-to-twin transfusion syndrome truly superior to the standard selective technique? A meta-analysis. Fetal Diagn Ther 2015;37:251-258.
61 Peeters SH, Akkermans J, Westra M, Lopriore E, Middeldorp JM, Klumper FJ, Lewi L, Devlieger R, Deprest J, Kontopoulos EV, Quintero R, Chmait RH, Smoleniec JS, Otano L, Oepkes D: Identification of essential steps in laser procedure for twin-to-twin transfusion syndrome using the Delphi methodology: SILICONE study. Ultrasound Obstet Gynecol 2015;45:439-446.

62 Groenendaal F, Termote JU, van der HeideJalving M, van Haastert IC, de Vries LS: Complications affecting preterm neonates from 1991 to 2006: what have we gained? Acta Paediatr 2010;99:354-358

63 Mulder EE, Lopriore E, Rijken M, Walther FJ, te Pas AB: Changes in respiratory support of preterm infants in the last decade: are we improving? Neonatology 2012;101:247-253.

64 Ancel PY, Goffinet F; EPIPAGE-2 Writing Group, Kuhn P, Langer B, Matis J, Hernandorena X, Chabanier P, Joly-Pedespan L, Lecomte B, Vendittelli F, Dreyfus M, Guillois B, Burguet A, Sagot P, Sizun J, Beuchée A, Rouget F, Favreau A, Saliba E, Bednarek N, Morville P, Thiriez G, Marpeau L, Marret S, Kayem G, Durrmeyer X, Granier M, Baud O, Jarreau PH, Mitanchez D, Boileau P, Boulot $\mathrm{P}$, Cambonie G, Daudé H, Bédu A, Mons F, Fresson J, Vieux R, Alberge C, Arnaud C, Vayssière C, Truffert $P$, Pierrat V, Subtil D, D’Ercole C, Gire C, Simeoni U, Bongain A, Sentilhes L, Rozé JC, Gondry J, Leke A, Deiber M, Claris O, Picaud JC, Ego A, Debillon T, Poulichet A, Coliné E, Favre A, Fléchelles O, Samperiz S, Ramful D, Branger B, Benhammou V, Foix-L'Hélias L, Marchand-Martin L, Kaminski M: Survival and morbidity of preterm children born at 22 through 34 weeks' gestation in France in 2011: results of the EPIPAGE-2 cohort study. JAMA Pediatr 2015;169:230-238.

65 van Klink JM, Koopman HM, Oepkes D, Walther FJ, Lopriore E: Long-term neurodevelopmental outcome in monochorionic twins after fetal therapy. Early Hum Dev 2011; 87:601-606.

66 Chalouhi GE, Essaoui M, Stirnemann J, Quibel T, Deloison B, Salomon L, Ville Y: Laser therapy for twin-to-twin transfusion syndrome (TTTS). Prenat Diagn 2011;31:637646. 